\title{
The Influence of Relative Sliding Speeds on the Tribology Characteristic of the Steel-cast Iron Friction Pair in the Self-repairing Additive
}

\author{
Yanhong Yan \\ College of Mechanical Engineering ${ }^{1}$, \\ Aviation Key Laboratory of Science and Technology on \\ Generic Technology of Self- \\ Lubricating Spherical Plain Bearing ${ }^{2}$ \\ Yanshan University \\ Qinhuangdao, China \\ yhyan@ysu.edu.cn \\ Yanhong Xia \\ College of Mechanical Engineering ${ }^{1}$, \\ Aviation Key Laboratory of Science and Technology on \\ Generic Technology of Self- \\ Lubricating Spherical Plain Bearing ${ }^{2}$ \\ Yanshan University \\ Qinhuangdao, China \\ 1249719003@qq.com
}

\author{
Xiaoting Shi \\ College of Mechanical Engineering ${ }^{1}$, \\ Aviation Key Laboratory of Science and Technology on \\ Generic Technology of Self- \\ Lubricating Spherical Plain Bearing ${ }^{2}$ \\ Yanshan University \\ Qinhuangdao, China \\ 793365990@qq.com \\ Xuchao Chen \\ College of Mechanical Engineering ${ }^{1}$, \\ Aviation Key Laboratory of Science and Technology on \\ Generic Technology of Self- \\ Lubricating Spherical Plain Bearing ${ }^{2}$ \\ Yanshan University \\ Qinhuangdao, China \\ 1031253392@qq.com
}

\begin{abstract}
To find out the influence of different relative sliding speeds on frictional wear characteristics of $45 \#$ steelcast iron friction pair under the 46\# machine oil that includes the self-repairing additive condition, MMU-5G endface friction and wear testing machine were used to do the experiment and then the surface images of friction pair and their chemical composition were detected by using SEM and EDS. Besides, the capability of generating self-repair coatings on the $45 \#$ steel friction surface were verified in the self-repairing additive. The result indicates different relative sliding speeds have a great influence on frictional wear characteristics of $45 \#$ steel-cast iron pair in the self-repairing additives. In conclusion, for the steel-cast iron friction pair in the self-repairing additive, the self-repair coatings are formed on the 45\#steel worn surface with the load of $200 \mathrm{~N}$ and the relative sliding speed of $0.553 \mathrm{~m} / \mathrm{s}$, and the additive has remarkable effect on antifriction and wearing of cast iron.
\end{abstract}

Keywords-Steel-cast Friction Pair; Self-repairing Additive; Relative Sliding Speeds; Frictional Wear Characteristics; Mechanism Analysis

\section{INTRODUCTION}

Wear is one of the three main forms (wear, corrosion, fatigue fracture) of material failure; it is a major reason that reduces the efficiency and accuracy of machines, indeed make the machines retirement.[1] Therefore, it is particularly urgent and important to improve the existing part's life and repair the worn parts to achieve saving materials, reducing energy consumption and enhancing economic efficiency.
Metal wear self-repairing technology uses mineral powder lubricant composition, and the energy condition provided by friction system prompts friction chemical, electrochemical, mechanical-chemical and force chemical reaction adequately between metal wear self-repairing additive and the contact surface materials of friction pair, in order to achieve the online self-repair on micro-worn surface dynamically. In recent years, the metal selfrepairing additive has been studied more extensively [2-5]. Fro $m$ the experiment, it can be seen that hydroxide radical magnesium silicate mineral powder additives do have good self-repairing properties[6-8]. The frictional wear characteristic of each friction pair in the self-repairing additive has been studied more extensively, and great progresses have been made on the research of analyzing and discussing the self-repairing mechanism[9-12]. Metal wear self-repairing technology has made remarkable achievements in practical application, but as conditions and mechanism of self-repairing coatings' conformation have not been fully recognized, the promotion and application of the technology is limited.

The relative sliding speed of friction pair has an important influence on friction-generated heat, reaction rate of friction chemical, wear rate, stress state of friction pair. XU ,Xiangjie, et al, studied the effect of sliding velocity on the wear behavior of monocry stalline silicon under various contact size by nanoscratch and servo hydraulic dynamic test machine. It turns out that with the increase in the sliding velocity, more cracks are initiated, tinier wear debris is generated, and less wear volume is 
observed. In addition they may not only help the improvement of the nanofabrication technique of silicon, but also optimize the tribological design of micro electromechanical system[13]. LIN Fu-dong, et al, conducted Friction and wear tests by using the HDM-20 tribometer under oil lubrication conditions to get the effects of friction speed and load on its tribological performance. The results show that the friction coefficient decreases, the mass wear loss and the friction surface temperature increase with the increase of friction speed and load[14].

Due to the current researches in this field focus on the steel - steel pairs, there are few study and related report about the frictional wear characteristics of cast iron in selfrepairing additive. In view of this, the paper made a series of studies on frictional wear characteristics of cast iron in the home-made hydroxide silicate lubricant additive, and this paper investigates influence and mechanism of frictional wear characteristics of $45 \#$ steel-cast iron friction pair under the 46\# machine oil that includes the selfrepairing additive condition with different relative sliding speeds.

\section{TEST PART}

\section{A. Self-repairing Additive}

The additive used in the test is hydroxide radical magnesium silicate (serpentine), Equipment used is the GN-2 high-energy globe mill. After milled, the size of powder particle of additives is around $200 \mathrm{~nm}$.

\section{B. Tribology Experiment}

The experiments of tribology used MMU-5G screenending-face friction and wear test machine. The upper specimen is ordinary cast iron (HT200); and the under specimen is $45 \#$ steel. Self-repairing additive is $2 \%$, at room temperature, friction and wear experimental time is 24hours, and the additive is scattered for $20 \mathrm{~min}$ in $46 \#$ mechanical oil by ultrasonic, lubricated with oil pool. Before and after the experiment, all specimens should be cleaned for $15 \mathrm{~min}$ by ultrasonic in the acetone solution. After being dried in the atmosphere, the mass of the specimen should be measured by the sensor electronic scales whose precision is $0.1 \mathrm{mg}$. In the experiment, the influence of the relative sliding speed on friction and wear characteristics is studied with load of $200 \mathrm{~N}$. The worn surface and cross-section of the specimen are observed by the new field emission scanning electron microscopy (SEM), the sample surface composition is tested by EDS.

\section{TEST RESULTS AND ANALYSIS}

\section{A. The Influence of Friction and Wear Properties}

\section{1) The impact of mass loss}

Fig. 1 shows the wear mass loss curve of the upper and under samples with different relative sliding speeds. It can be seen that, the relative sliding speed of the friction pair impacts wear mass loss very observably. The variation of the two curves is consistent, in the initial experiments, they both increase with the rise of relative sliding speeds, when reach the maximum value, they begin to decrease. The upper sample curve reaches the maximum with the relative sliding speeds of $0.276 \mathrm{~m} / \mathrm{s}$, then wear mass decreased significantly, and it is a negative value with the relative sliding speeds of $0.691 \mathrm{~m} / \mathrm{s}$, it indicates that there is an increase in the quality of the specimen at this time; and the under sample achieves the maximum when the relative sliding speed is $0.139 \mathrm{~m} / \mathrm{s}$, then wear mass declines slowly.

2) Influence of friction coefficient

Fig. 2 shows the coefficient curve under different relative sliding speeds conditions. variations of the friction coefficient curves are consistent, all decline rapidly in the initial experiment, and then stabilized. Therefore, the friction coefficient is high when the relative sliding speed is $0.139 \mathrm{~m} / \mathrm{s}$, and under the other three working conditions, the friction coefficients increase with relative sliding speeds' rise. Experimental data shows that, stable friction coefficients are as follows: the friction coefficient is 0.002 with speed of $0.139 \mathrm{~m} / \mathrm{s}$; the friction coefficient is the minimu $\mathrm{m}$, for 0.001 , with speed of $0.276 \mathrm{~m} / \mathrm{s}$; the friction coefficient is 0.0015 with speed of $0.553 \mathrm{~m} / \mathrm{s}$; the friction coefficient is maximum, for 0.0025 , with speed of $0.691 \mathrm{~m}$ / s.

\section{3) SEM observation of worn surface and EDS test}

Fig. 3 shows the SEM photographs of worn surface of cast iron with different relative sliding speeds. With speed of $0.139 \mathrm{~m} / \mathrm{s}$, the sample surface has obvious scratches and furrows, spalling occurs in many small areas; with speed of $0.276 \mathrm{~m} / \mathrm{s}$, the sample surface has a small a mount of minor scratches and a very small amount of furrows, no peeling basically, there is clear smooth region; with speed of $0.553 \mathrm{~m} / \mathrm{s}$, there are fewer scratches and furrows, and no obvious peeling in local area ; with speed of $0.691 \mathrm{~m} / \mathrm{s}$, the scratches are very serious, furrows are more deep, but there are still no large areas of spalling.

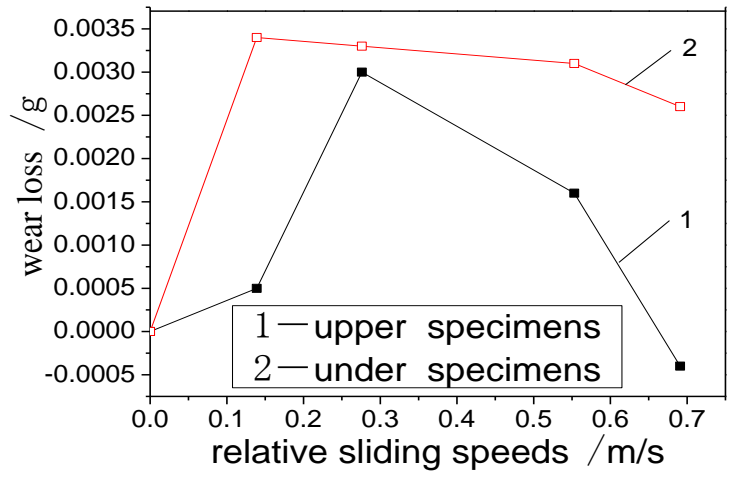

Figure 1. Wear mass loss of samples in different relative sliding speeds conditions

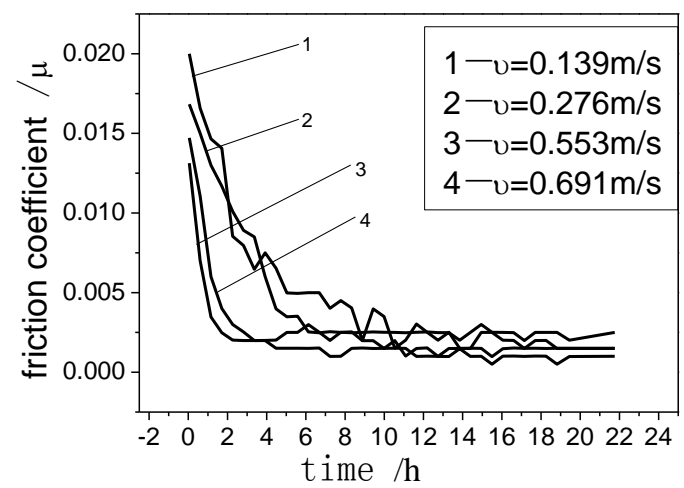

Figure 2. The curve of Friction coefficient under different relative sliding speeds 
Fig. 4 is the EDS photos of worn surface of cast iron with and without additives. Experiments show that the two energy spectra images are basically the same, but the contents of $\mathrm{C}$ and $\mathrm{O}$ are slightly higher on the friction surface under additives, after analysis, it is believed that $\mathrm{C}$ and $\mathrm{O}$ come from the decomposition of lubricating oil and $\mathrm{Mg}_{21} \mathrm{Si}_{12} \mathrm{O}_{28}(\mathrm{OH})_{34} \cdot \mathrm{H}_{2} \mathrm{O}$, which is the main component of self-repairing additives. The specimen surface was not found to have main component of repair materials, the $\mathrm{Mg}$ and $\mathrm{Si}$ elements.

Studies have shown that friction modification layers or self- repairing coatings can be generated on the friction surface of the steel - steel friction pair under the metal selfrepairing additives conditions. This experimental result shows that when $45 \#$ steel matches with cast iron, the selfrepairing coatings can still be generated on the friction surface. Through observing SEM photographs of samples with different speeds by scanning electron microscopy, it can be seen that under certain operating conditions, there is a thin layer of material that combines with substrate well on the 45\# steel substrate, as shown in Fig.5 (a). The corresponding energy spectra (c) also displays that this layer contains $\mathrm{Mg}$ and Si elements, they are included in the main body of self-repairing additives, it shows a selfrepairing response occurs during the friction wear progress and comparing spectrum (b) and (d) of cast iron with Fig. 4 (a) under the same working conditions, there are no external elements on the surface.

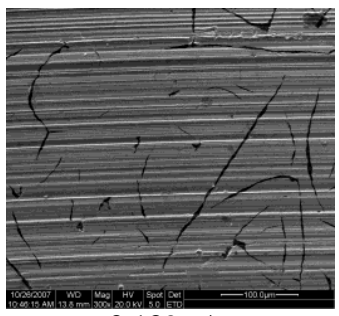

$0.139 \mathrm{~m} / \mathrm{s}$

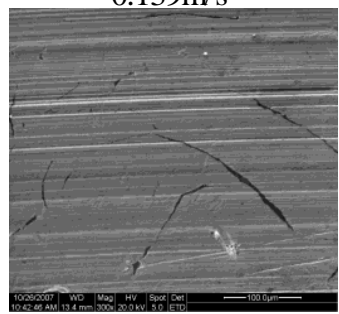

$0.553 \mathrm{~m} / \mathrm{s}$

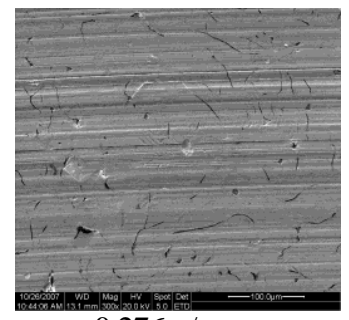

$0.276 \mathrm{~m} / \mathrm{s}$

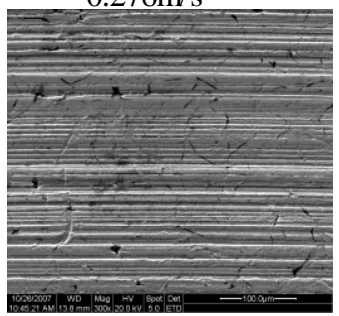

$0.691 \mathrm{~m} / \mathrm{s}$
Figure 3. SEM photographs of worn surface of cast iron under different relative sliding speeds conditions (for grinding 24h)

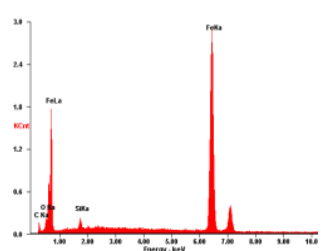

(a) $0 \%$ additive

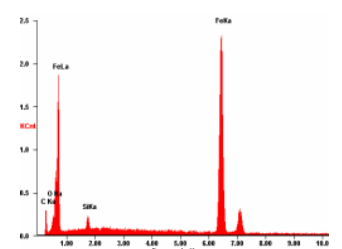

(b) $2 \%$ additive
Figure 4. EDSimages of surface of cast iron under different lubrication conditions the specimens is larger in the initial running; the reason is that the original samples' surface is rough after line-cutting, in the initial experiment, burr is worn away. from the energy spectra of under sample (Fig. 6), it can be seen that the surface of $45 \#$ steel has main elements of additives, it indicates that repair materials particulate be squeezed into the concaves and pores, the energy released by friction of the steel and cast iron samples is enough to stimulate friction chemical and electrochemical reaction, with instantaneous high temperature and pressure generated in the local contact area on friction surface, micro-sintering and micro-metallurgical process occur, a layer of metalceramic repairing coating is formed on the surface of friction pair, it expresses as the increases of quality.

Because graphite exists in cast iron as the lamellar structure, so when the friction pair slides, the graphite on the surface is a good solid lubricant, at the same time, it can absorb and preserve oil, holes forms after graphite falling off the metal substrate, and they can also save the lubricant, and promote the formation of lubricant film, thereby the wear of cast iron surface reduces, so the wear quality of cast iron is bound to be less than $45 \#$ steel.

With lower relative sliding speeds, such as speed of $0.139 \mathrm{~m} / \mathrm{s}$, speed of $0.276 \mathrm{~m} / \mathrm{s}$, the contact surface of the samples can not produce enough friction chemical reaction activation energy, and thus can not promote to occur friction chemical reaction which can generate selfrepairing coating. The increase of sliding speed is conducive to generate oil film on the surface of friction pair, and reduce wear degree, it is expressed that the wear mass decreases at speed of $0.276 \mathrm{~m} / \mathrm{s}$, and at the speed of $0.691 \mathrm{~m} / \mathrm{s}$, the wear mass is higher,it can lead to friction chemical reaction occur between the friction pairs, but because the relative sliding speed between the friction pairs is too high, self-repairing protective film may be wear away soon after its formation, thus, the film is difficult to survive; only with the appropriate relative sliding speed of $0.553 \mathrm{~m} / \mathrm{s}$, the self-repairing protective film can be retained (as shown in Fig. 5 (a)). The relative sliding speed of $0.139 \mathrm{~m} / \mathrm{s}$ is too low to make a lubricant film generated on the surface, as the speed increasing, the films on the friction surface are more and more continuous, thus reduce friction and wear on the friction surface. If the speed is too high, the formation of the oil film will be destroyed, and that is the reason why friction coefficient is the lowest with speed of $0.276 \mathrm{~m} / \mathrm{s}$, but with speeds of $0.553 \mathrm{~m} / \mathrm{s}$ and $0.691 \mathrm{~m} / \mathrm{s}$, friction coefficient increases with the increase of the speed.

Generally, it is considered that the strength of cast iron is lower than steel, its surface is more easily to be destroyed and exposed, in the case that high temperature and pressure, namely "flash temperature", continues to occur, it would be easier to generate self-repairing protective layer, but this experiment proves that selfrepairing film does not generate on the worn surface of cast iron. It is considered that the key to form selfrepairing protective films on metal worn surface is the occurrence of micro-metallurgical reactions, due to the microstructure and mechanical performance of cast iron,

4) Mechanism Analysis.

From analyzing the wear mass curves with different sliding speeds (Fig. 1), it can be found that the mass loss of 


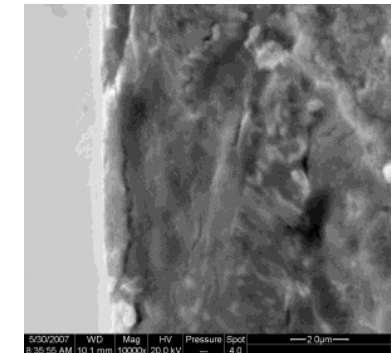

(a) $45^{\sharp} \operatorname{steel}(v=0.553 \mathrm{~m} / \mathrm{s})$

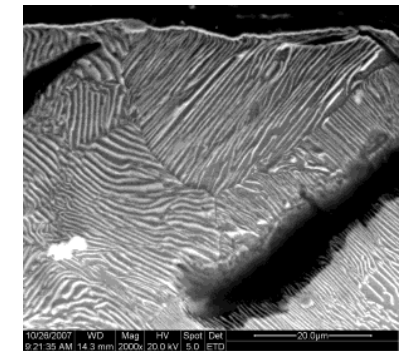

(b) Cast iron $(v=0.553 \mathrm{~m} / \mathrm{s})$

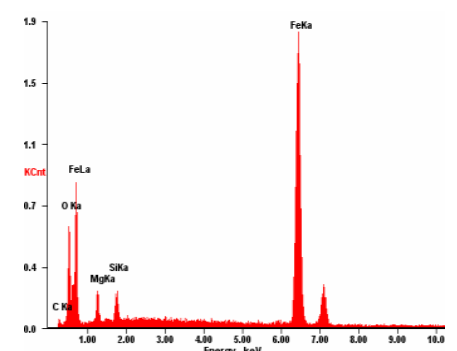

(c) EDS images corresponding (a)

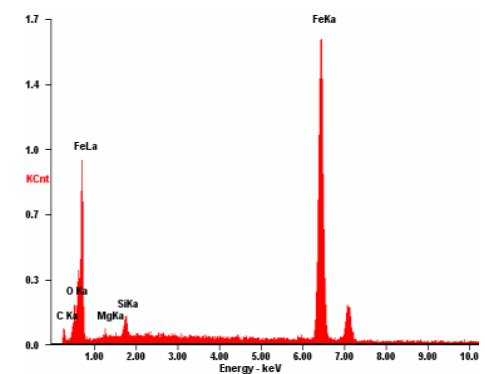

(d) EDS images corresponding (b)

Figure 5. SEM images of cross-section of samples under different conditions and the corresponding energy spectrum Photos

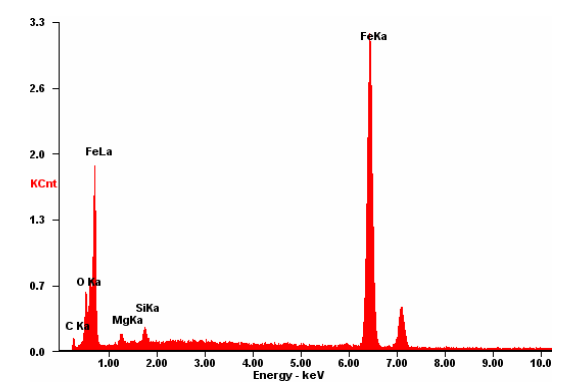

Figure 6. EDS images of surface of $45 \#$ steel under $v=0.276 \mathrm{~m} / \mathrm{s}$

When the sliding speeds are small, a thick graphite ball me mbrane is easy to be formed on the surface of cast iron, and it blocks the repair material particles to enter into the friction surface; when the sliding speeds increase, although the graphite globule membrane is destroyed, due to the cast iron's strength and hardness are low, the additive particles are easily cutting out from cast iron after they are embedded in cast iron surface, the additive particles are taken away by the cast iron filings under higher speed conditions, the additive particles are difficult to remain in the cast iron base, there is no sufficient time to occur micro-metallurgical process, therefore, it is difficult to form a self-repairing coating on the friction surface of cast iron.
The effect of antifriction and anti-wear is notable under suitable amount of additives condition, the reason is considered to be the physical effect of additive particles. After additives applied in the friction pair, they are continued to be smashed to tiny particles under the pressure and shear force that exist between the friction pair, the motion on the friction surface is relatively easy to scroll, especially the powders that are closely in the shape of spherical and rod-shaped can play the role of Microballs, they can change sliding friction into rolling friction between friction pairs, and reduce the friction coefficient; particles have mic ro-grinding effect on actual contact spots of the surface of friction pair, making them smooth, reducing friction and wear. Thus, though there is no selfrepairing protective coating generated on the friction surface of cast iron, additives improve antifriction and anti-wear significantly.

\section{CONCLUSIONS}

1. Different relative sliding speeds have a great influence on frictional wear characteristics of $45 \#$ steel cast iron pair. The friction coefficient is the minimum, for 0.0010 , with speed of $0.276 \mathrm{~m} / \mathrm{s}$, the friction coefficient is the maximum, for 0.0025 , with the maximum relative sliding speed of $0.691 \mathrm{~m} / \mathrm{s}$.

2. When the relative sliding speeds are too small, the energy released by friction effect of friction pair is not enough to stimulate friction chemical reaction; when $45 \#$ steel matches with cast iron, there are self-repairing protective coatings generated on the surface with load of $200 \mathrm{~N}$ and speed of $0.553 \mathrm{~m} / \mathrm{s}$.

3 . Though there is no self-repairing protective coating generated on the friction surface of cast iron, additives improve antifriction and anti-wear properties significantly.

\section{REFERENCES}

[1] Yulin Qi, Friction and Wear [M]. Beijing: High Education Press, 1986.

[2] Cao Yang, Zhou Yuan-kang, Zhang Da-bin, Yang Lv, Zhu Wenxian, "Effect of Nano-Montmorillonite Additive on Tribological Properties of 45 Steel Tribo-pair, "Lubrication Engineering, vol.39, No.9, sept.2014, pp.46-51, doi:10.3969/j.issn.02540150.2014.09.010.

[3] TIAN Bin, WANG Cheng-biao, GU Yan-hong, YUE Wen, MA Xiang-dong, LIU Jia-jun, "Effect of a cermet additive in lubricating oil on tribological performance of steel/steel friction pair," Transactions of Materials And Heat Treatment,vol.27,No.3,2006, pp.132-136, doi:10.3969/j.issn.10096264.2006.03.029

[4] WU Xue-mei, ZHOU Yuan-kang, YANG Lu, WANG Chen-xiang, LI Yi, CHEN Jian-hai, "Effect of Nanopalygorskite Additive in Base Oil on Anti-wear and Selfrepairing Properties of 45\# Steel Tribo-pair," Journal of Materials Engineering, No.4,2012, pp.82-87.

[5] LI Zheng WANG Wen-jian LIU Qi-yue, "Effect of Nanoadditive on Friction and Wear Performance of GCr1S/1045 Steels," China Surface Engineering, vol.24, No.6, Dec. 2011,pp.68-72, doi:10.3969/j.issn.1007-9289.201 1.06.012.

[6] ZHU Gong-zhi, GAO Yu-zhou, LIU Shi-yong, ZHANG Hui-chen, "Antiwear and Self- repairing Mechanisms of Magnesium Hydroxysilicate Composite Powder as a Lubricating Oil Additive for Steel- Steel Pair,"Tribology, vol.32, No.2, 2012, pp.183-188.

[7] CHENWen-gang, GAO Yu-zhou, ZHANG Hui-chen, TAN Ze-fei, "Self-repairing Characteristics of Superfine Powder of Hydroxyl Magnesium Silicate On a Worn Steel Surface," Journal of the Chinese ceramic society, vol.38, No.4, Apr.2010, pp.762-767. 
[8] PENG Yong-fu, YIN Bao-feng, SHAO Xin, "Application of the New Type of RestorationMaterial for Metal Anti abrasion, "Ship\&Ocean Engineering, vol.42, No.2, Apr.2013, pp.83-86, doi:10.3963/j.issn.1671-7953.2013.02.026.

[9] XIN Xi-ling, XU Xiao-jing, TIAN Kun, FAN Zhen, CHEN Dan, "Friction and Wear Behaviors of Steels-steels Fiction Pairs under Different Lubricating Conditions," Machinery Design \& Manufacture, No.3, Mar.2012, pp.213-215.

[10] MA Yu-hong, YANG Hong-wei, YANG Shi-liang, YAOT ing, LI Zhao-liang, "Development Stat us of Frication and Wear Lubricant Additive with Self-remediation Function," Guangzhou Chemical Industry, vol.41, No.7, Apr.2013, pp.32-33, doi:10.3969/j.issn.1001-9677.2013.07.013.

[11] LIU Qing, CHANG Qiu-ying, DU Yong-ping, JIN Yuan-Sheng, "Research Progress of Hydroxyl Silicate as Self-repairing
Lubricating Oil Additive," Bullet in of The Chinese Ceramic Society, vol.30, No.4, Aug.2011, pp.840-844.

[12] Zhu Wen-xiang, Zhou Yuan-kang, Yang Lv, Zhu Chi, "Influence of Nano-mont morillonite Lubricant Additive on Friction and Wear Properties of Metal Friction Components," Non-Metallic Mines, vol.35, No.4, July.2012, pp.79-81, doi:10.3969/j.issn.10008098.2012.04.026

[13] XU Xiang-jie, YU Bing-jun, CHEN Lei, et al, "Effect of Sliding Velocity on the Wear Behavior of Monocrystalline Silicon under Various Cont act Size," Journal of Mechanical Engineering, vol.49, No.1, Jan.2013, pp.235-240, doi:10.3901/JME.2013.01.108.

[14] LIN Fu-dong, HUANG Ping, YIN Yan-guo, "Effects of Sliding Speed and Load on Tribological Performance of Lead-free Copper-bismuth Bearing Materials,"Materials Science and Engineering of Powder Metallurgy, vol.18, No.2, Apr.2013, pp. $108-114$. 